This item was submitted to Loughborough's Research Repository by the author.

Items in Figshare are protected by copyright, with all rights reserved, unless otherwise indicated.

\title{
Knowledge management practices in large construction organisations
}

PLEASE CITE THE PUBLISHED VERSION

PUBLISHER

(C) Emerald Group Publishing Limited

VERSION

AM (Accepted Manuscript)

LICENCE

CC BY-NC-ND 4.0

REPOSITORY RECORD

Robinson, Herbert S., Patricia M. Carrillo, Chimay J. Anumba, and Ahmed M. Al-Ghassani. 2019. "Knowledge Management Practices in Large Construction Organisations". figshare. https://hdl.handle.net/2134/4190. 
This item was submitted to Loughborough's Institutional Repository (https://dspace.lboro.ac.uk/) by the author and is made available under the following Creative Commons Licence conditions.

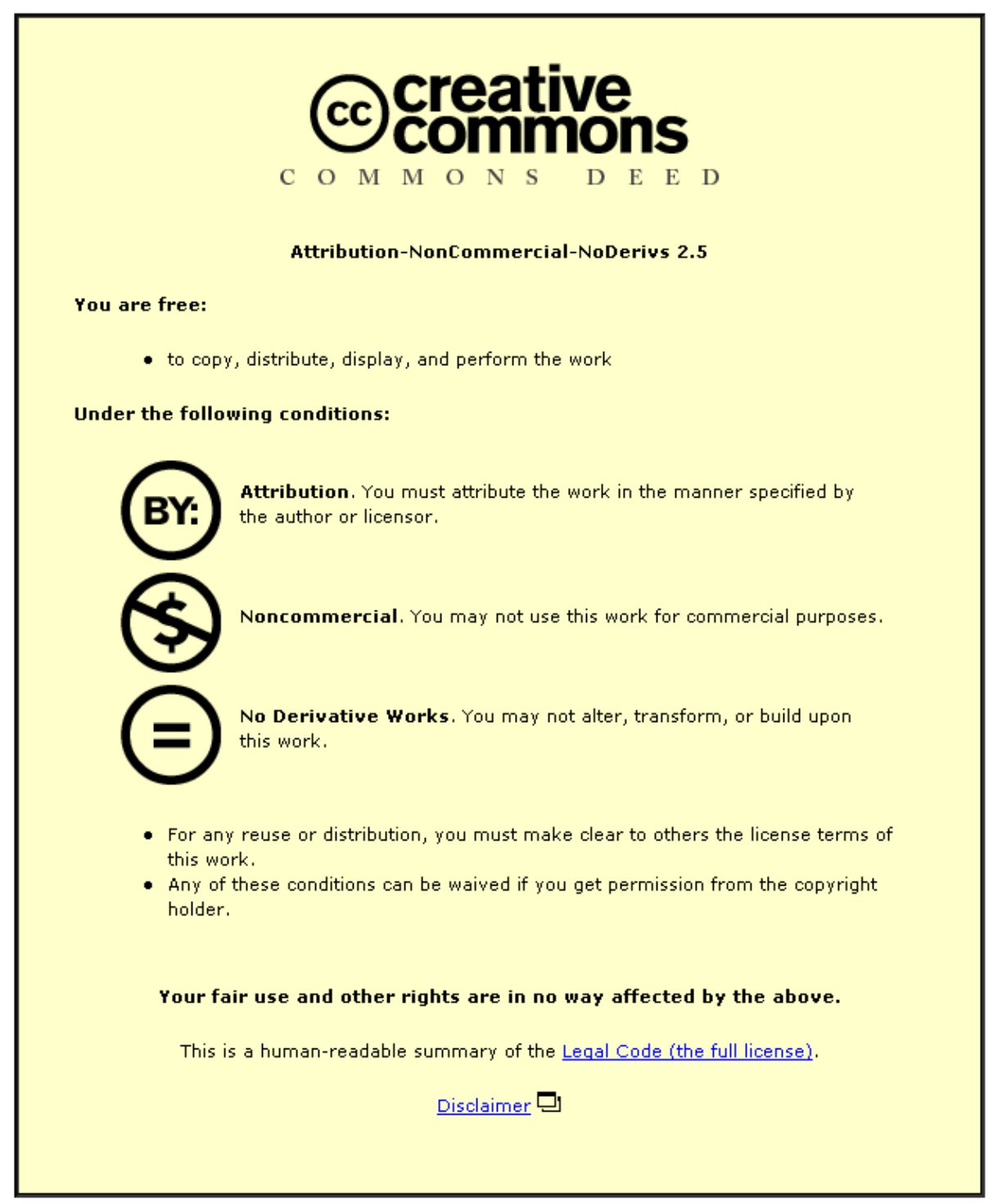

For the full text of this licence, please go to: http://creativecommons.org/licenses/by-nc-nd/2.5/ 


\section{Knowledge Management Practices in Large Construction Organisations}

Herbert S. Robinson ${ }^{1}$, Patricia M. Carrillo ${ }^{2}$, Chimay J. Anumba ${ }^{3}$ and Ahmed M. Al-Ghassani ${ }^{4}$

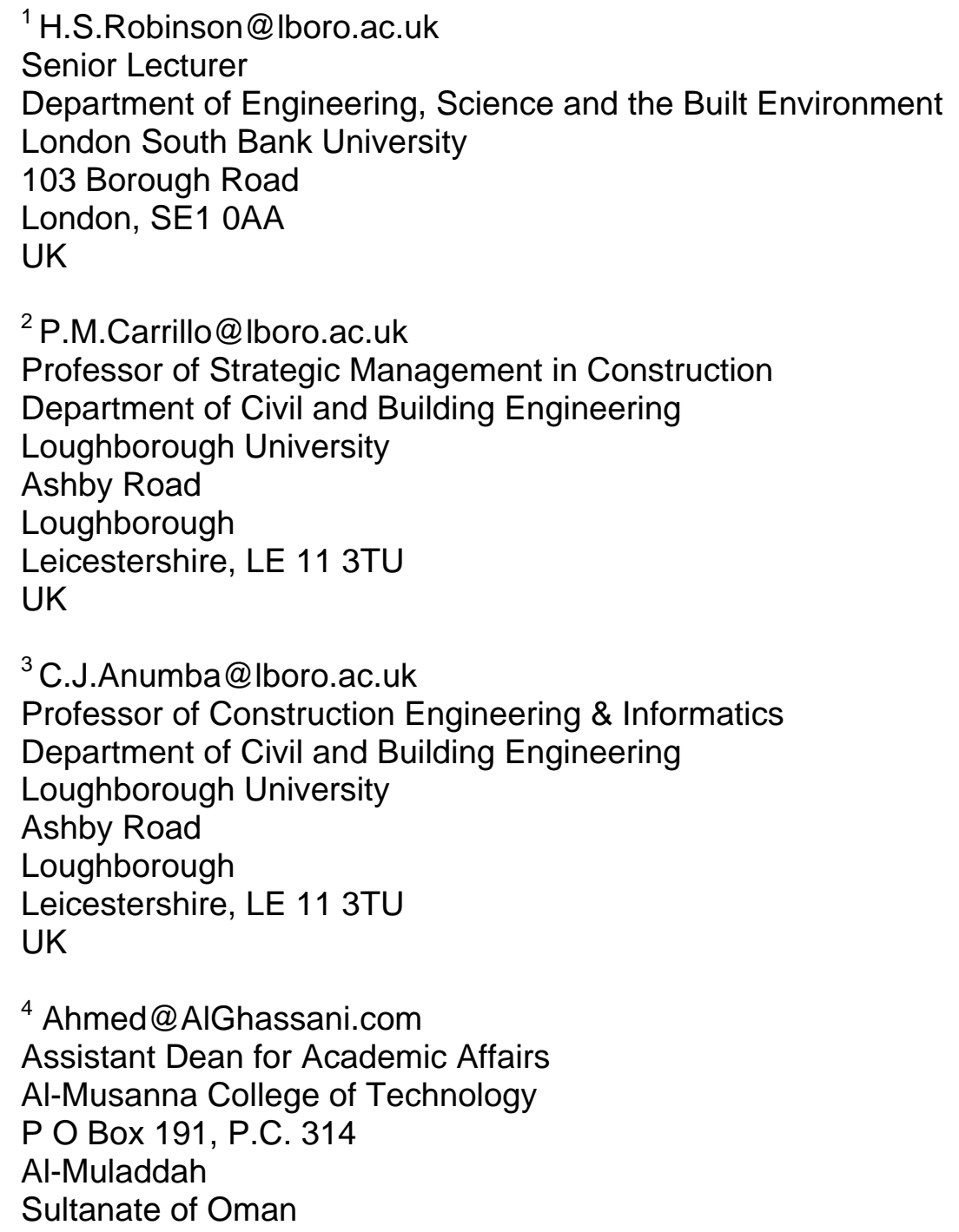

Word Count: 5,430 excluding reference list 


\title{
Knowledge Management Practices in Large Construction Organisations
}

\author{
Abstract \\ Purpose - This paper investigates how large UK construction organisations manage \\ their knowledge assets. It then proposes STEPS, a mechanism for benchmarking \\ organisation's knowledge management maturity. \\ Design/methodologylapproach - This paper adopts a case study methodology using \\ four large UK construction organisations. \\ Findings - The investigation shows that the UK-based companies with international \\ operations are ahead of their national counterparts in their KM implementation efforts. \\ The paper concludes that construction organisations are likely to be successful in \\ implementing KM if appropriate considerations are given to strategy formulation, \\ implementation issues addressed and the link between $\mathrm{KM}$ and business strategy is \\ strengthened.
}

Originality/Value - The paper proposes mechanism, entitled STEPS for benchmarking the maturity of large construction organisations knowledge management practices. It then uses case study organisations to demonstrate how the STEPS model should be used.

Key words Knowledge management, construction organisations, benchmarking, UK Paper Type Research Paper 


\section{Introduction}

Major construction industry reviews in the UK have identified the need for continuous performance improvement (Latham, 1994; Egan, 1998). The most recent review by Fairclough (2002) also recognised the need for improvements but emphasised the importance and role of innovation in the overall construction process. Learning and knowledge sharing are essential drivers of innovation in order to sustain the long-term competitive advantage of organisations. The industry has also been made increasingly aware of knowledge sharing through initiatives such as the Construction Best Practice Programme (CBPP) and Movement for Innovation (M4I).

Knowledge is the hidden asset of organisations, which has to be nurtured for long-term corporate sustainability (Edvinnson, 1997) and knowledge management is a method of exploiting, or transforming knowledge as an asset for organisational use to facilitate continuous improvement. However, $\mathrm{KM}$ is a recent and evolving practice, particularly for construction organisations. A recent survey of leading construction organisations in the UK shows that about $42 \%$ have a KM strategy, and $32 \%$ plan to have a strategy within a short term (Carrillo et al, 2004). Over $90 \%$ of larger organisations (employing more than 1,500 ) have or intend to have a strategy compared to half of the smaller organisations (employing less than 500). The results suggest that: (1) KM is becoming increasingly important in the construction context; and (2) KM appears to be more important to larger organisations as it is difficult to determine 'who knows what' in such organisations (Davenport and Prusak, 1998). Larger organisations are also more likely to have a leader or a KM champion and to have the resources to support a KM strategy. Patel et al (2000) argued that KM and organisational learning are recognised by the larger construction firms as potentially important but little has been attempted at a formal level. Whilst an increasing number of construction organisations now perceive KM as an 
integral aspect of business improvement, there are major difficulties associated with its application such as establishing a strategy, identifying the resources and reform needed and evaluating its benefits.

This paper presents evidence on the state of $\mathrm{KM}$ in large construction organisations in the UK. The paper is divided into six sections as follows: KM Considerations; Case Study Objectives and Methodology; KM Practices of the case study organisations; Analysis and Discussion; and Conclusions.

\section{KM Considerations}

Knowledge is vital for business improvement but "it is not the knowledge of the organisational members per se which is of critical strategic importance, it is the firm's productivity in building, integrating and utilising its intellectual capital which is vital" (Jordan and Jones, 1997). There are several dimensions of organisational knowledge; individual and group knowledge, internal and external knowledge, and tacit and explicit knowledge (Al-Ghassani et al, 2002). However, one of the most practical distinctions is that between tacit and explicit knowledge (Nonaka and Takeuchi, 1995). Tacit knowledge is stored in the heads of individuals and is difficult to communicate externally or to share. Explicit knowledge is captured or stored in an organisation's manuals, procedures, information systems, and is easily communicated or shared with other people or parts of an organisation.

\section{Knowledge in the Construction Context}

There is a need to structure or classify the knowledge an organisation is interested in terms of its business context. Context-based factors relate to what an organisation 
produces (products in terms of goods and services), what processes are required and what people are employed. Bennett (1991) identified three distinct end products: standard construction, traditional construction and innovative construction. These products rely on a mix of tacit and explicit knowledge. For example, innovative products require a higher degree of tacit knowledge (Bennett, 2000). Product knowledge also relates to knowledge about different client types, associated relationships and market characteristics. Process factors relate to the technical and management systems used in production. Technical processes could be highly labour-intensive relying on tacit knowledge or automated based on explicit (codified) knowledge in computer systems. Management processes range from programmed to problem-solving organisations. Problem-solving organisations rely on tacit knowledge to produce innovative projects. This is necessary to fulfil clients' design and construction requirements that cannot be met by established answers (Bennett, 2000). People factors relate to the characteristics of individuals and teams. While appropriate management structures are necessary, competent teams (suppliers, designers and constructors) are vital for the construction process.

Matusik and Hill (1998) argued that the relationship between organisational knowledge and competitive advantage is moderated by an organisation's ability to integrate and apply knowledge. The key issue, therefore, is to identify localised knowledge and transform it into productive knowledge that resides within the organisation and creates value (Stewart, 1997). Developing a strategy to manage knowledge therefore requires an understanding of the dimensions of knowledge and its business context.

\section{Knowledge Management Strategy}


Knowledge management relates to unlocking and leveraging the different types of knowledge so that it becomes available as an organisational asset. Implementing KM enables an organisation to learn from its corporate memory, share knowledge, and identify competencies in order to become a forward thinking and learning organisation. O'Leary (2001) argued that KM initiatives can help attract and nurture top talent, as 'maximising access to knowledge across the organisation' can accelerate the learning experience of new employees, build more knowledge and increase organisational capability. KM can drive innovation, helps to attract new and retain valuable customers, and in the process increase organisational productivity and profitability. Demarest (1997) noted that 'firms without knowledge management systems will be effectively unable to achieve the re-use levels required by the business model implicit in the markets they enter, and will lose market share to those firms who do practice knowledge management'.

There are two distinct strategies identified for developing KM systems: codification and personalisation (Hansen et al, 1999). A codification strategy revolves around explicit knowledge captured and leveraged using IT-tools i.e. software such as expert systems, artificial intelligence and data mining tools. Personalisation, at the other extreme, revolves around tacit knowledge using non-IT tools or human interactive systems such as knowledge sharing networks (Dyer and Nobeoka, 2000), communities of practice (Wenger et al, 2002, brainstorming and post- project reviews, etc.

In a codification strategy, IT can be used to make intelligent decisions, whereas in a personalisation strategy, IT provides communication support. Incentives and reward schemes may be necessary to encourage knowledge sharing and has been identified as one of the critical success factors for KM (Hall et al, 2000). There are also different types 
of incentives or rewards - financial, promotional or peer acclaim. However, a key issue in the application of KM is the evaluation of the likely outcome or benefits. Dent and Montague (2004) has suggested that 'it may be more appropriate to scrutinise, review and celebrate success rather than develop specific KM measurement'. They foresee a need for more detailed measures when KM activity matures within the company. A major challenge for those with responsibility for $\mathrm{KM}$, therefore, is to make a strong business case and to convince senior management and other employees about the potential benefits (Davenport et al, 1997). 


\section{Case Study Objectives And Methodology}

This study forms part of a three-year research project investigating the relationship between knowledge management and business performance. The objective of the study was to assess $\mathrm{KM}$ practices and the factors influencing the development of $\mathrm{KM}$ based on case studies of four construction organisations. A two-stage approach was used to highlight key issues on KM prior to conducting the case studies. Firstly, the literature review and initial discussions with companies participating in the project provided the basis for identifying key issues in KM. Secondly, an exploratory survey was carried out on the perception of $\mathrm{KM}$ in engineering and construction organisations using a sample of 170 leading organisations in the UK. The findings indicated that over three-quarters of organisations were aware of the benefits of $\mathrm{KM}$ and the same amount intended to have a KM strategy in the short -term, over $45 \%$ of organisations intended to have a person or group with responsibility for KM and a lack of standard work processes posed a barrier to KM (Carrillo et al., 2004). A case study approach was selected for further exploration as it provides an in-depth insight on how $\mathrm{KM}$ is planned, implemented and evaluated. This involved identifying suitable persons in each organisation and conducting semi-structured, open-ended interviews.

The interviews focused on key themes of KM such as the organisations' goal, KM strategy, the tools for implementing KM, barriers, and the evaluation of $\mathrm{KM}$. A number of questions were specifically aimed at investigating the links between $\mathrm{KM}$ and business strategy, and the use of the Balanced Scorecard (Kaplan and Norton, 1996) and the Excellence Model (EFQM, 1999) as strategic frameworks for performance improvement. The Balanced Scorecard was developed in the US and is a performance improvement model that encourages organisations to adopt a more holistic and proactive approach towards measuring their performance. It looks at four main areas: Customer 
Perspective; Financial Perspective; Internal Business Perspective; and Learning and Growth Perspective. The Excellence Model is a European model that adopts a similar approach but uses nine criteria divided into Enablers and Results. The Enablers are Leadership, People, Policy and Strategy, Partnerships and Resources and Processes. The Results are: People, Customer, Society and Key Performance.

Four organisations were investigated reflecting a balanced mix of two national and two international firms. Face-to-face interviews were conducted with senior personnel who were asked to respond to questions from an organisational rather than a personal perspective. A total of fourteen people were interviewed including a chief knowledge officer, a knowledge manager, IT/systems managers, financial directors, technical/group directors, business/continuous improvement managers, and business development managers. Between two to five people were interviewed in each organisation, with the range of people reflecting the different perspectives of $\mathrm{KM}$ in the case study organisations. The KM approaches adopted by case study organisations are presented in the next section.

\section{The Case Studies}

The case studies reflect the experiences of some of large UK construction organisations in the application of $\mathrm{KM}$. Each case explores $\mathrm{KM}$ in terms of strategy, implementation and evaluation. The results of four case studies are reported below. The four organisations were selected based on (a) their responses to questionnaire survey of 170 UK consulting and contracting organisations; and (b) their involvement in ongoing KM research projects. The case studies were considered atypical of the spread of responses obtained and include two international and two national firms. 
Company A is a UK-based company with international operations. It employs over 8,500 staff and has a turnover of over $£ 2.1$ billion. It has traditionally been involved in a wide range of construction activities from landmark buildings to heavy civil engineering structures but has now extended its activities to include housing and property development. The company's KM activities started about ten years ago, in the form of a 'help desk' operated by technical service teams for site engineers. The appointment of a Knowledge Manager in 2000 led to a formal approach to KM. A Knowledge Editor, a Technical Services team and an Intranet team support the Knowledge Manager.

Company B is a UK company with over 1500 employees and an annual turnover of over $£ 900$ million. The company's predominant focus is on whole life construction and it is involved in a wide range of activities including both buildings and civil engineering projects. They are in the process of reviewing their IT strategy, and are taking the opportunity to look at associated KM issues with a view to developing a KM strategy.

Company $\mathrm{C}$ is a UK-based company with international operations employing about 50,000 employees and with an annual turnover of over $£ 4$ billion. The company's predominant focus is on engineering design ranging from buildings to heavy civil engineering projects. It has recently been restructured following a high profile merger with a large international professional services group. A Chief Knowledge Officer (CKO) was appointed in 2000. This position enjoys a high level of management support and reflects the company's commitment to managing its intellectual assets. The CKO reports directly to a line manager who is on the Executive Board. 
Company $\mathrm{D}$ is a UK organisation involved in construction projects from design and construction to facilities management. It has been involved in major restructuring leading to down-sizing and a change of strategic direction. It employs over 250 people and has an annual turnover of over $£ 100$ million. There is no specific manager or post dedicated to KM, but the Information Systems Manager and Systems Administrator undertake some KM activities. A KM strategy is being formulated.

Table 1 below compares and contrasts the four case study organisations with respect to key attributes associated with the development of KM.

$<$ Take in Table 1>

\section{Analysis And Discussion}

The case studies provide a snapshot of how KM is practised in four large construction organisations. The measures adopted and the progress of the case study organisations are discussed below.

\section{Strategic Considerations}

KM Awareness

All the case study organisations are aware of the importance of knowledge sharing and the benefits of KM but there some differences in perception. Some organisations perceive $\mathrm{KM}$ as synonymous with managing information. There is clearly a difference between knowledge and information, and this difference is not academic. As Malhotra (2000) explained 'this strategic difference is not a matter of semantics; rather, it has critical implications for managing and surviving in an economy of information overabundance and information overload'. The purpose of $\mathrm{KM}$ or the role of a 
Knowledge Manager is also misunderstood in some organisations. The narrow interpretation of $\mathrm{KM}$ implies that the role of Knowledge Manager is sometimes wrongly perceived to be that of a technical librarian for managing information on the Intranet. There is also the misconception of a Knowledge Manager as somebody who knows 'everything about everything'. A Knowledge Manager is simply a facilitator or, using Skandia's concept of a tree metaphor, a 'gardener' to nurture the roots of organisational knowledge. The role of knowledge manager needs to be communicated in some organisations to facilitate knowledge sharing and to dispel fears sometimes associated with KM such as job insecurity.

\section{KM Goal and Strategy}

The primary goal or motivation for $\mathrm{KM}$ varies from seeking best practices in all business activities to providing a better service to clients. However, the overall objective is to improve project or business performance and indirectly to increase profitability. Two case study organisations already have a KM strategy, one is in the process of fine-tuning its strategy whilst the other plans to have a strategy in the short term. The absence of a working definition of what constitutes knowledge to underpin the KM strategy in some organisations reflects the casual approach to $\mathrm{KM}$ and an indication of the need for further exploration of $\mathrm{KM}$ issues.

\section{Structure of the KM Strategy}

All the case study organisations argued that the talents of their people are crucial and are, or will be, central to any KM strategy. As one senior director put it 'I can think certainly we have to start with people, we are not manufacturing nuts and bolts - we are out there selling a service - professional project management service in the main and that depends on the expertise, training ... and ability of our people'. Processes are also 
recognised as an important aspect. Two of the organisations have been involved in high profile merger and acquisition activities recently. The implication is that these organisations are now suffering from having too many different processes, which makes knowledge sharing difficult. These organisations are now undertaking a major restructuring of their business processes to identify problem areas, clarifying the users and sources of knowledge, in order to facilitate knowledge sharing. Some organisations also recognise the importance of their products, but the product aspect of KM is often overlooked. Whilst it is the tacit knowledge of people that is more valuable for engendering innovation (Egbu 2000), it is ultimately the products that determine whether an organisation will remain competitive. However, none of the organisations appears to have a coherent structure for looking at knowledge management requirements in terms of the relationships between people, processes and products (Robinson et al 2001). KM strategies are more likely to be successful if there is a structure for identifying the relationships between the types of knowledge required with clear priorities to avoid chaos or an 'archipelago of knowledge islands' (APQC 1997).

\section{Implementation}

KM Resources

Some organisations enjoy a higher degree of top management support than others. Senior management support and leadership for KM is vital. The two international organisations have established full-time KM positions - a chief knowledge officer and a knowledge manager. The two national companies do not have designated KM positions but have assigned $\mathrm{KM}$ responsibilities to various personnel. Whilst it is true that the function or role is more important than the title, support for KM by individuals as part of their normal jobs can be a source of distraction, as they can be vulnerable to pressures from other conflicting activities. Also, to add $\mathrm{KM}$ as another responsibility without 
increasing resources is not feasible. It may, at best, downgrade its profile or, at worst, there may be strong resistance to $\mathrm{KM}$, which can lead to it not being taken seriously.

$\mathrm{KM}$ strategies also need to be fully resourced in terms of KM teams to support the leadership, a budget and an infrastructure. The two organisations with a KM strategy and the third organisation currently fine-tuning its strategy have employed additional staff. A budget of $£ 500,000$ was specified in one organisation, but remained undisclosed in the other two cases for commercial reasons. The use of external consultants is limited to one organisation, where the consultant was asked to review how knowledge could be captured from processes, as part of a change management programme. All the case study organisations have an Intranet that is used to support KM, although some are more advanced than others.

\section{IT-Based KM Tools}

The case study organisations have a number of IT and non-IT systems for implementing $\mathrm{KM}$. The Intranet is the backbone of the IT infrastructure but there are concerns about content management, access, validation and editorial issues. Content validation is a key problem associated with the use of Intranets. Some organisations have a clear validation procedure or mechanism whilst others do not. However, the need for a validation mechanism for putting items onto the Intranet with clearly defined processes and process owners is generally recognised as crucial. Extranets are also used but this is a more recent development and generally limited to certain projects in some organisations. However, its use should be promoted, as a useful tool for collaborative work to facilitate knowledge sharing within project teams and the entire construction supply chain. 
Non IT-Based KM Tools

There is a perception in some organisations that information technology is central to KM. Some argue that 'there is a powerful symbiotic relationship between knowledge management and information technology' (APQC, 1997), as an increasing amount of corporate knowledge is now available on Intranets and other IT-based systems. However, there is widespread evidence that most organisational knowledge is in people's heads and processes, and IT is not capable of capturing some tacit knowledge without losing its context. For example, Malhotra (2000) argued that there is a 'dangerous perception about knowledge management as seamlessly entwined with technology'. Davies et al (1998) argued for new ways of transmitting knowledge through organisations as a large amount of the knowledge within an organisation is personal, context-specific and difficult to write down. Thus, more effort should be directed in setting up and enhancing systems to facilitate person-to-person and person-toorganisation interactions.

The two international organisations are currently using Skills Yellow Pages whilst one of the national organisations is exploring this facility for locating tacit knowledge i.e. to find the right person to approach for advice and best practice. A leading UK consulting organisation, has Skills Yellow Pages that puts staff in contact with not just another person, but that individual's network and reference material (Sheehan, 2000). Such a tool is very important to organisations but needs to be kept up-to-date to maintain its usefulness. Other non-IT tools used for knowledge sharing include communities of practice, task teams, and quality circles. 'Share Fair' was used as a high profile event in one organisation to encourage a knowledge sharing culture. 


\section{Reward schemes}

None of the organisations have reward schemes for knowledge sharing. Financial reward systems are difficult to put into operation and organisations must therefore tread carefully. A CKO argued that 'the real things in $\mathrm{KM}$ are the soft rewards, feeling good about being contacted or appreciated by colleagues as an expert'. This view is supported by Sheehan (2000) who argued that peer acclaim is more likely to be successful. Imposing incentive schemes for willingness to share and use knowledge may, at best, be difficult to monitor and, at worst, be seen as divisive. Monitoring willingness to share can be subjective, inflated to attract rewards, and could lead to what Lawton (2000) described as the 'development of knowledge landfills'.

\section{Barriers to $K M$}

Organisational culture is considered one of the most crucial factors contributing to the success of a KM project, and 'perhaps the most difficult constraint that knowledge managers must deal with' (Davenport et al, 1997). The case studies confirm that organisational culture is a key barrier but this has not yet been addressed in most organisations. KM is not only a technical problem involving the use of IT but a sociocultural one involving motivating people 'to make them willing to yield up this knowledge for organisational use' (Marshall and Sapsed, 2000). Only one organisation has implemented a change management programme to strengthen the relationship between teams and to inculcate a positive attitude to knowledge sharing and recognition. There is the need to proactively tackle organisational culture, and associated barriers such as people's fears, attitudes or resistance to knowledge sharing. Other barriers identified include initiative overload, bureaucracy associated with KM, poor IT infrastructure, lack of top management support, conflicting priorities between $\mathrm{KM}$ and other business functions and the difficulties associated with communicating the benefits of KM. 


\section{Evaluation of KM Performance}

Relationship between KM and business strategy

The case studies show a recognition that $\mathrm{KM}$ needs emphasis but there are difficulties in demonstrating its benefits to senior management. $\mathrm{KM}$ is not explicitly linked to their business strategy or strategic objectives. Both the Balanced Scorecard and the Excellence Model are used by the case study organisations as frameworks for business improvement and provide a basis for developing KM. However, the learning and knowledge dimension of both models are often overlooked in practical applications. In identifying the links between the KM and business strategies, the relationships between the teams are also crucial. A senior business improvement manager working with a colleague on establishing a knowledge repository argued that $90 \%$ of the knowledge captured in two main areas of expertise of the firm will be lost if they leave the organisation. This highlights the need for KM strategy to address both tacit and explicit knowledge.

\section{Monitoring and communicating the benefits of KM}

Several of the organisations have identified demonstration projects as KM initiatives. However, appropriate methods are not put in place to monitor and communicate the benefits of $\mathrm{KM}$ initiatives. Publicising the results of $\mathrm{KM}$ initiatives can help maintain $\mathrm{KM}$ as a high profile activity and increase the level of awareness, even after the initial interest has waned. Performance measures currently being used or developed in some organisations could be linked to KM initiatives. A full-scale measurement framework could be developed as an organisation evolves to a stage where $\mathrm{KM}$ implementation is mature, well co-ordinated and sustained. However, it is recognised that organisations at 
the lower levels of KM maturity may need to start with basic qualitative performance measures to monitor and review the benefits (APQC, 2001; Dent and Montague, 2004).

\section{Benchmarking KM Activities}

The case studies illustrate that construction organisations are at varying levels of implementing $\mathrm{KM}$. They range from organisations that have made limited progress as a result of approaching KM without a dedicated leadership and an under-resourced KM plan to organisations that have made reasonable progress mainly due to a KM strategy supported by a leadership and dedicated resources. One way of finding out where an organisation stands in terms of KM maturity is to benchmark their activities with other organisations. Dent and Montague (2004) attempted to benchmark organisations but the result does provide a mechanism for allowing organisations to see where they stand compared to leading UK construction companies. One proposal to assess KM maturity is provided in the following section.

\section{Maturity Stages}

A KM maturity roadmap (STEPS) was developed based on attributes discussed in the case studies (see Figure 1). The five steps (Start-up, Take-off, Expansion, Progressive, and Sustainable) show the various levels of KM maturity. The attributes reflect key issues in KM such as awareness of the benefit of knowledge sharing, the need to identify the reform needed, the resource implications and the need for a result monitoring system to review the impact of KM. Each attribute also has dimensions of low, medium and high performance to indicate their position within each stage. This allows companies to refine their position if they have only met some of the attribute's requirements. 
$<$ Take in Figure 1>

Organisations at the Start-up stage are characterised by some understanding of the importance of knowledge sharing, awareness of the benefits of $\mathrm{KM}$, and how it could be applied for business improvement. For organisations at the most advanced stage, the Sustainable stage, $\mathrm{KM}$ is expected to be a normal routine, diffused in the entire organisation, as it becomes an integral part of the organisational culture, employees' behaviour, business processes and product development. This is also referred to as the institutionalisation of KM (APQC, 2001). The following provides typical characteristics of each stage.

\section{Start-up Stage}

Organisations at this stage are the least advanced and are characterised by:

- An understanding of the concept of $\mathrm{KM}$, different perspectives of $\mathrm{KM}$ and its practical implications;

- An appreciation of the benefits of $\mathrm{KM}$, at least, in theory;

- Recognition of the potential of $\mathrm{KM}$ in building the value of knowledge assets for continuous improvement; and

- Establishing the need for KM and the willingness to share knowledge

\section{Take-off Stage}

The Take-off stage involves:

- Establishing the goals of $\mathrm{KM}$;

- Exploring strategic options. This could be demand driven (delivered in real time where and when it is needed) or supply driven (available in a central repository). 
The focus could be on people interactions (personalisation) or documents or IT (codification);

- Developing a KM strategy with a working definition to facilitate consensus;

- Establishing leadership and identifying resources for consultancy and support;

- Identifying barriers and risks associated with the strategy and possible changes required; and

- Experimentation of KM on an ad hoc basis, localised or very small scale.

\section{Expansion Stage}

The Expansion stage is characterised by:

- Refining the KM strategy and linking KM activities to specific business objectives;

- Increasing the visibility of KM leadership, and the allocation of resources (budget, staff, IT infrastructure);

- Implementing a change management programme to address barriers and risks identified;

- Implementing KM initiatives in a structured and co-ordinated way, and identifying appropriate KM tools to support specific initiatives;

- Increasing the scale of KM initiatives to other business units, projects and offices;

- Introducing performance measures to evaluate $\mathrm{KM}$; and

- Communicating the benefits of knowledge assets.

\section{Progressive Stage}

The Progressive stage is characterised by: 
- Integrating KM activities into strategic measurement frameworks such as the Balanced Scorecard and the Excellence Model to monitor and evaluate knowledge assets;

- Establishing evaluation criteria and targets for measuring the impact on knowledge assets and justifying KM initiatives;

- Introducing reward and incentive schemes to strengthen KM activities; and

- Increased visibility and communication of the benefits from most KM activities.

\section{Sustainability Stage}

At the Sustainable stage, KM becomes institutionalised and is characterised by:

- KM becoming linked to all business objectives;

- $\mathrm{KM}$ practices diffused in the entire organisation;

- KM becoming embedded in organisational culture, employees' behaviour, business processes and product development; and

- Widespread reporting on the performance of knowledge assets underpinning corporate sustainability.

Within each stage a low, medium and high rating is used to indicate whether the characteristics are superficially, partially evident, fully evident respectively.

\section{Case studies' KM Performance}

Figure 2 shows the position of the case study organisations in the KM maturity scale. The black ovals indicate ratings based on the interviewees' perception of the current positions of their companies. The white ovals show the research team's assessment of the relative positions of the case study organisations. STEPS was developed based on 
a detailed literature review, responses to a questionnaire survey and the case studies conducted.

$<$ Take in Figure 2>

The researchers' ratings are based on an analysis of the key attributes of KM using the STEPS maturity roadmap. The assessment shows that two organisations have overestimated their level of maturity, one has under-estimated it, while the fourth has made a reasonably accurate estimate. In terms of achievements, two organisations are at the Start-Up stage, one is at the Take-off stage and one is at the Expansion stage. The two case study organisations ( $A$ and $C$ ) leading the maturity scale are international companies. The remaining two (B and $D$ ) are national, UK-based companies at the Start-up stage, exploring KM, often without resources and a dedicated leadership to direct their KM strategy. These findings suggest that there is a greater need for larger international organisations to implement KM systems as they tend to have a significant amount of knowledge that is more diverse and geographically dispersed to manage. However, a wider study of organisations will be required to confirm this. It also shows that there is still a considerable amount of work to be done before any of these organisations achieve the Sustainable stage.

\section{Conclusions}

There is a growing awareness of the need for a structured approach to KM across a wide range of industry sectors. Construction organisations are keen to benchmark their $\mathrm{KM}$ activities in an effort to improve performance. This paper investigated the KM activities of four leading construction organisations using a case study methodology. 
The areas investigated were their KM strategy, implementation and the evaluation methods used to judge the success of their KM initiatives as well as the linkages between $\mathrm{KM}$ and business strategy.

In implementing $\mathrm{KM}$, organisations should consider the following factors:

- The need to develop a strategy which clearly defines the objectives of KM implementation;

- Resources including a budget and management support are essential for KM implementation success;

- Recognition that necessary reform such as organisational culture needs to be addressed to facilitate $\mathrm{KM}$ implementation;

- KM strategy needs to be supported by both IT and non-IT tools to be successful. IT tools address the explicit knowledge component whereas non-IT tools address the tacit knowledge component;

- It is important to link KM to existing performance measures; and

- There is a need for a KM maturity scale to enable organisations to objectively benchmark their KM implementation efforts.

The STEPS framework indicated that the larger international organisations, often geographically distributed, are ahead of national, UK-based, companies in terms of the progress on KM. However, further research will be needed to confirm this finding.

Construction organisations are keen to exploit any mechanism that encourages better performance. $\mathrm{KM}$ is now seen as a contributory factor in business improvement. However, organisations are more likely to be successful in implementing KM if 
appropriate measures are adopted, implementation issues addressed and the link between $\mathrm{KM}$ and business strategy strengthened.

\section{Acknowledgements}

The research project was sponsored by the Engineering and Physical Sciences Research Council (EPSRC) and a number of industrial collaborators in the UK. Their contributions to the project and in the development of this research paper are acknowledged. 


\section{References}

Al-Ghassani, A.M, Robinson, H.S., Carrillo, P.M. and Anumba, C.J. (2002),"A Framework for Selecting Knowledge Management Tools". Proceedings of the $3^{\text {nd }}$ European Conference on Knowledge Management (ECKM), Dublin, Republic of Ireland, 37- 48.

APQC (1997), "Using Information Technology to Support Knowledge Management: Consortium Benchmarking Study." (Final Report), American Productivity \& Quality Center Texas, USA

APQC (2001) "Measurement for Knowledge Management." American Productivity \& Quality Center, http://www.apqc.org/free/articles/dispArticle.cfm?ProductID=1307 on 6 March 2002

Bennett, J. (1991), International Construction Project Management: General Theory and Practice, Butterworth-Heinemann Ltd, Oxford.

Bennett, J. (2000), Construction - The Third Way, Managing Cooperation and Competition in Construction, Butterworth-Heinemann Ltd, Oxford.

Carrillo, P.M, Robinson, H.S, Al-Ghassani, A.M and Anumba, C.J (2004), "Knowledge Management in Construction: Drivers, Resources and Barriers", Project Management Journal, Vol. 35 No. 1, pp. 46-56.

Dent, R.J. and Montague, K.N. (2004), Benchmarking knowledge management practice in construction, CIRIA Report C620, London.

Davenport, T and Prusak, L. (1998) Working Knowledge: How organisations manage what they know. Harvard Business School Press.

Davenport, T.H., De Long, D.W. and Beers, M.C. (1997), "Building Successful Knowledge Management Projects." Centre for Business Innovation, Ernst \& Young, Working Paper, January. 
Davies, N.J., Stewart, R.S. and Weeks, R. (1998), "Knowledge Sharing Agents over the World Wide Web." BT Technology Journal, Vol 16 No. 3, pp.104-109.

Demarest, M. (1997), "Understanding Knowledge Management." Long Range Planning, Vol. 30, No. 3, pp. 374 -384.

Dyer, J.H. and Nobeoka, K. (2000), "Creating and Managing a High Performance Knowledge Sharing Network: The Toyota Case." Strategic Management Journal, 21, pp. $345-367$.

Edvinnson, L, (1997), "Developing Intellectual Capital at Skandia." Long Range Planning, Vol. 30 No. 3, pp. 366-373.

EFQM (1999), "Eight Essentials of Excellence: The Fundamental Concepts and their Benefits." European Foundation for Quality Management, Brussels.

Egan, J. (1998), "Rethinking Construction", Report of the Construction Task Force on the Scope for Improving the Quality and Efficiency of the UK Construction Industry, Department of the Environment, Transport and the Regions, London.

Egbu, C. (2000), "The Role of Tacit and Explicit Knowledge in Improving Organisational Innovations in Architecture, Engineering and Construction", Joint Meeting of CIB W55/W65 and TG31/TG35, Reading, UK, 15 September.

Fairclough, J. (2002), "Rethinking Construction Innovation and Research: A review of Government R \& D Policies and Practices, Department for Transport and Local Government Regions (DTLR), London.

Hall, J., Sapsed, J. and Williams, K. (2000), "Barriers and Facilitators to Knowledge Capture and Transfer in Project-Based Firms." Knowledge Management: Concepts and Controversies Conference, University of Warwick, 10-11 February.

Hansen, M.T. Nohria, N. Tierney, T. (1999), "What's Your Strategy for Managing Knowledge." Harvard Business Review, March-April, pp. 106-116. 
Jordan, J. and Jones, P. (1997), "Assessing your Company's Knowledge Management Style." Long Range Planning, Vol. 30 No 3, pp. 392-398.

Kaplan, R.S. and Norton, D. P. (1996), "The Balanced Scorecard - Measures that Drive Performance." Harvard Business Review, Vol 70 No 1, pp. 71-79.

Latham, M. (1994), "Constructing the Team", Final Report on the Joint Review of Procurement and Contractual Arrangements of the UK Construction Industry, HMSO, London.

Lawton, P. (2000), "Moving Knowledge Management Beyond Technology", PricewaterhouseCoopers, http://www.pwcglobal.com , accessed 02/05/00.

Malhotra, Y. (2000), Knowledge Management for E-Business Performance: Advancing Information Strategy to "Internet Time." Information Strategy, The Executive's Journal, Vol. 16 No 4, Summer, pp 5-16.

Marshall, N. and Sapsed, J. (2000), The limits of Disembodied Knowledge: Challenges of InterProject Learning in the Production of Complex Products and Systems, Knowledge Management: Concepts and Controversies Conference, Univ. of Warwick, 10-11 Feb.

Matusik, S.F. and Hill, C.W.L (1998), "The Utilization of Contingent Work, Knowledge Creation and Competitive Advantage." Academy of Management Review, Vol 23 No 4, pp. 680-697.

Nonaka, K., and Takeuchi, H. (1995), The Knowledge Creating Company: How Japanese Companies Create the dynamics of innovation, Oxford University Press, New York.

O'Leary, D.E. (2001), "How Knowledge Reuse Informs Effective System Design and Implementation." IEEE Intelligent Systems, January/February, pp 44-49.

Patel, M. B., McCarthy, T.J., Morris, P.W.G and Elhag, T.M.S (2000), "The Role of IT in Capturing and Managing Knowledge for Organisational Learning on Construction 
Projects." Proceedings of CIT 2000, Reykjavik, Iceland, 28-30 June, Gudnason, G. (ed.), pp. 674-685.

Robinson, H.S., Carrillo, P.M, Anumba, C.J and Al-Ghassani A.M. (2001) "Knowledge Management: Towards an Integrated Strategy for Construction Project Organisations." Proceedings of the Fourth European Project Management Institute (PMI) Conference, London, June 6-7, Paper published on CD.

Sheehan, T. (2000) "Building on Knowledge Practices at Arup." Knowledge Management Review, Vol 3 No 5, pp. 12- 15.

Stewart, T.A. (1997), Intellectual Capital: The New Wealth of Organisations, Doubleday Dell Publishing Group, New York.

Tiwana, A. (2000) The Knowledge Management Toolkit: Practical Techniques for Building a Knowledge Management System, Prentice-Hall, New Jersey. Wenger, E., McDermott, R. and Synder, W. (2000) Cultivating Communities of Practice, Harvard Business School Publishing, Massachusetts. 
Table 1: Comparison of KM Practices in case study organisations

\begin{tabular}{|c|c|c|c|c|}
\hline $\begin{array}{c}\text { KEY } \\
\text { CHARACTERISTICS }\end{array}$ & Case A & Case B & Case C & Case D \\
\hline Business activities & Contracting & Contracting & Consulting & Contracting \\
\hline Geographical focus & International & National (UK-based) & International & National (UK-based) \\
\hline KM definition available & Yes & No & Yes & No \\
\hline Goal of KM & $\begin{array}{l}\text { Improve technical } \\
\text { processes by } \\
\text { reducing mistakes } \\
\text { or sharing best } \\
\text { practices }\end{array}$ & $\begin{array}{l}\text { Provide better } \\
\text { service to clients }\end{array}$ & $\begin{array}{l}\text { Provide better value } \\
\text { and returns to } \\
\text { clients and } \\
\text { shareholders }\end{array}$ & $\begin{array}{l}\text { To get the best out } \\
\text { of people } \\
\text { employed and the } \\
\text { supply chain }\end{array}$ \\
\hline KM strategy & Yes & No & Yes & No \\
\hline Leadership for KM & Knowledge Manager & Finance Director & $\begin{array}{l}\text { Chief Knowledge } \\
\text { Officer }\end{array}$ & $\begin{array}{l}\text { Information Systems } \\
\text { Manager }\end{array}$ \\
\hline $\begin{array}{l}\text { Resources to support } \\
\text { KM strategy }\end{array}$ & $\begin{array}{l}\text { Budget }(£ 500,000) \\
3 \text { full-time Staff } \\
\text { IT Infrastructure }\end{array}$ & $\begin{array}{l}\text { No budget } \\
5 \text { Staff (on an ad } \\
\text { hoc basis) } \\
\text { IT infrastructure }\end{array}$ & $\begin{array}{l}\text { Budget (undisclosed) } \\
3 \text { full-time and } 25 \\
\text { part-time (on ad hoc } \\
\text { basis) Staff } \\
\text { IT Infrastructure }\end{array}$ & $\begin{array}{l}\text { Budget for external } \\
\text { consultants } \\
5 \text { Staff (on an ad } \\
\text { hoc/ volunteering } \\
\text { basis) } \\
\text { IT infrastructure }\end{array}$ \\
\hline Main KM tools & $\begin{array}{l}\text { Intranet } \\
\text { Project reviews } \\
\text { Site Liaison initiative } \\
\text { Technical call centre } \\
\text { Electronic Document } \\
\text { Management } \\
\text { System }\end{array}$ & $\begin{array}{l}\text { Intranet/ Extranet } \\
\text { Quality circles }\end{array}$ & $\begin{array}{l}\text { Skills Yellow Pages } \\
\text { Intranet/ Extranet } \\
\text { Communities of } \\
\quad \text { Practice } \\
\text { Share fair } \\
\text { Virtual work centre }\end{array}$ & $\begin{array}{l}\text { Intranet } \\
\text { Brainstorming } \\
\text { Electronic Document } \\
\text { Management } \\
\text { System }\end{array}$ \\
\hline $\begin{array}{l}\text { Intranet access, content } \\
\text { management and } \\
\text { validation approach }\end{array}$ & $\begin{array}{l}\text { Access to all staff } \\
\text { Individual dept own } \\
\text { information } \\
\text { No validation } \\
\text { mechanism }\end{array}$ & $\begin{array}{l}\text { Problems with } \\
\text { access } \\
\text { *No validation } \\
\text { mechanism }\end{array}$ & $\begin{array}{l}\text { Access to all staff } \\
\text { Heads of functions, } \\
\text { dept own } \\
\text { information } \\
\text { No validation } \\
\text { mechanism }\end{array}$ & $\begin{array}{l}\text { Information on } \\
\text { Intranet validated }\end{array}$ \\
\hline Barriers & $\begin{array}{l}\text { Organisational } \\
\text { culture } \\
\text { Change } \\
\text { management }\end{array}$ & $\begin{array}{l}\text { Organisational } \\
\text { culture } \\
\text { Employee } \\
\text { resistance } \\
\text { IT infrastructure }\end{array}$ & $\begin{array}{l}\text { Organisational culture } \\
\text { Initiative overload }\end{array}$ & $\begin{array}{l}\text { Conflicts between } \\
\text { KM activities and } \\
\text { day jobs } \\
\text { Unstructured KM } \\
\text { approach }\end{array}$ \\
\hline $\begin{array}{l}\text { Links between } \mathrm{KM} \text { and } \\
\text { business performance }\end{array}$ & None & None & None & None \\
\hline KM evaluated & No & No & Yes (basic measures) & No \\
\hline
\end{tabular}

* Intention to appoint somebody as Knowledge Manager or Web Master to police the system 


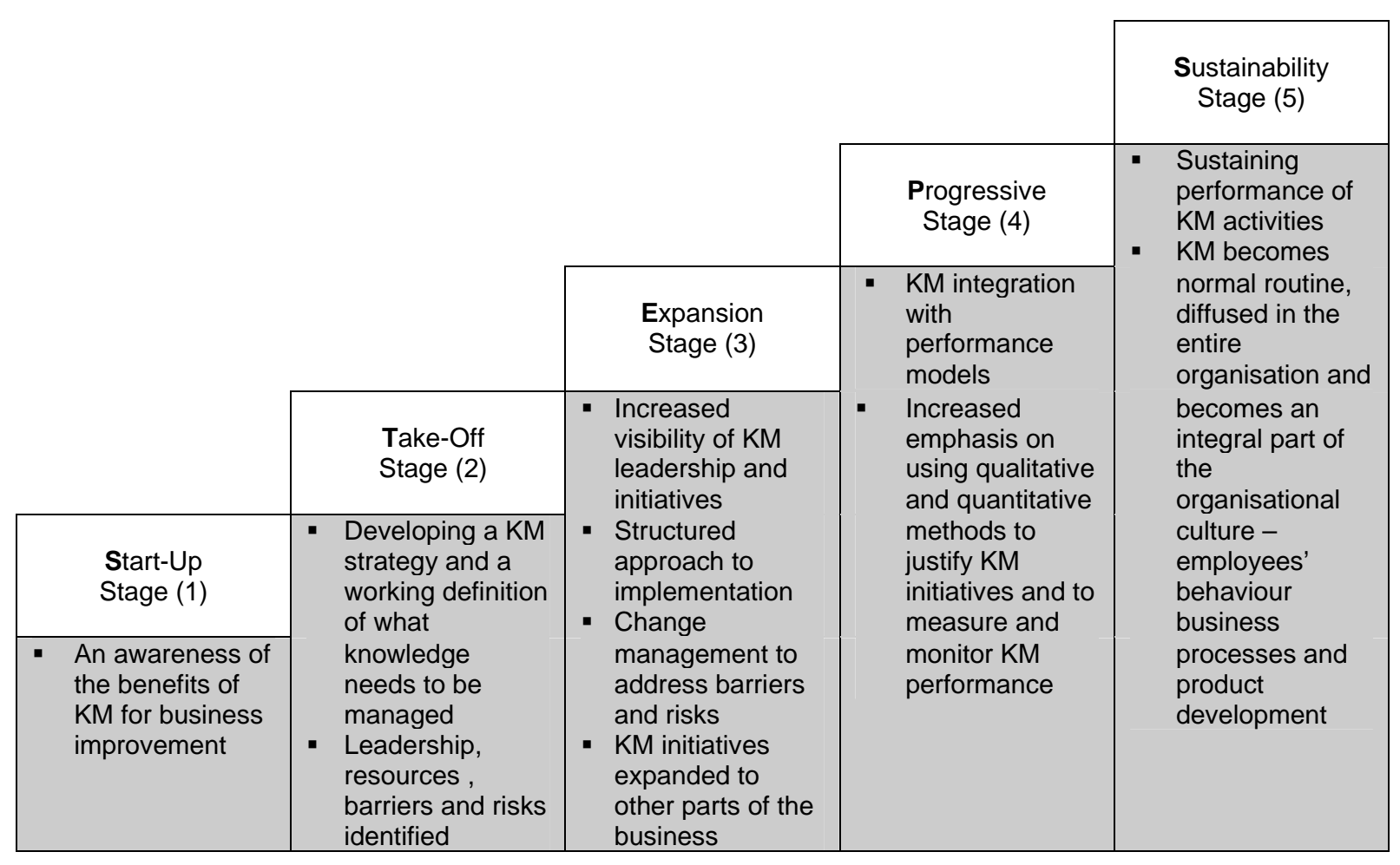

Figure 1: STEPS KM Maturity Stages 


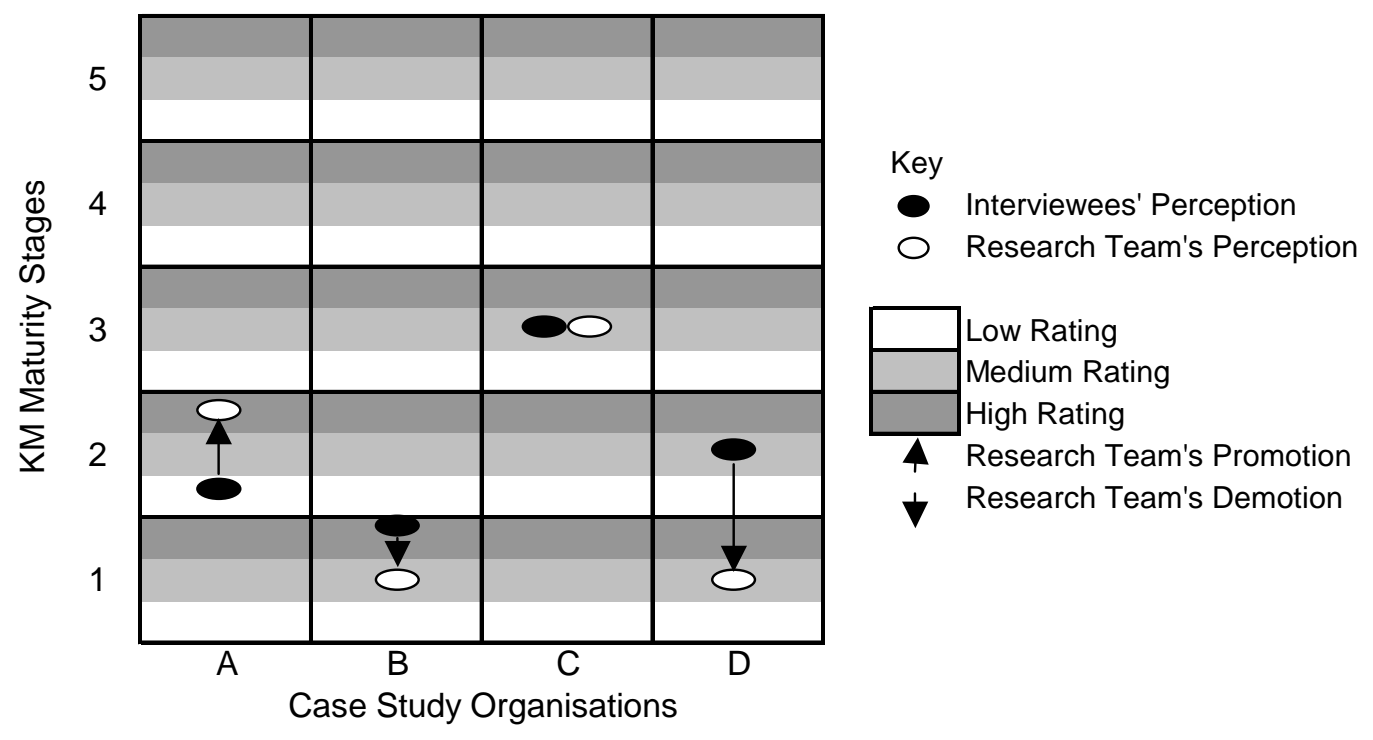

Figure 2: KM Maturity Stages of case study organisations 